\title{
Decision Support System for Indonesian Government Fast E-Tendering Based on Vendor Classification
}

\author{
Edi Wahyu Widodoํㅜ ${ }^{\text {, Tri Harsono }}{ }^{2}$, Ali Ridho Barakbah ${ }^{2}$ \\ Department of Graduate Program of Information and Computer Engineering \\ Electronic Engineering Politechnic Institute of Surabaya ${ }^{1,2}$ \\ Jalan Raya ITS Surabaya 60111, Indonesia \\ E-mail: wiedhodho@pasca.student.pens.ac.id, \{trison,ridho\}@pens.ac.id
}

\begin{abstract}
In the last few years in the world of auctions, electronic auctions become a hot topic for discussion, especially in Indonesia. In Indonesia, the auction has been using online electronic system since 2007 with all its advantages and disadvantages. This system is one of a fairly successful program in a good governance. Until now, there are 620 government agencies in Indonesia have been using this electronic procurement systems[19]. The Government can perform a budget efficiency nearly $5 \%$ of the total budget by using today's electronic procurement system. The current system is good enough, but there are still some deficiencies found. Some of solutions to cover the deficiency offered in this paper. Starting from the classification of goods or services according to the UNSPSC, applying business classification with ISIC Indonesia in 2009, recording the activity of vendors for consideration decision, and implementing a decision support system using AHP to facilitate the auction committee to determine the winner. All of above matters are intended to improve the effectiveness and efficiency of the current system.
\end{abstract}

Keywords: UNSPSC, KBLI 2009, E-Tendering, Text Mining, AHP.

\section{INTRODUCTION}

Presidential Decree No. 4 of 2015 [1] said that E-Tendering is a procedure to elect the vendor of goods / services which conducted openly and can be followed by all providers of goods or services listed on the electronic procurement system by submitting 1 (one) time offers within a predetermined time. In this e-tendering, there are alot of government funds were used to purchase goods and services. Government procurement of goods or services is a procurement of goods or services financed by the State Budget (APBN) / Budget (APBD), both carried out by themself as well as by providers of goods or services. The purpose of procurement of government goods or services are Obtaining goods or services at a price that can be accounted for, the amount and quality of appropriate and timely 
procurement. With the increasing development in our country, large increases in precisely the necessary funds for the procurement of government goods or services, both funds originating from within the country, and abroad. This requires attention and treatment earnest of users resulted in losses for the state.

Auction is a process of converting the government's money into goods/services. Goverment Procurement of goods or services are done by auction. This is a very important process because it uses substantial funds and be done continuously by a country. Procurement of goods or services that the government intended to obtain goods or services with the criteria of the right price, right (appropriate) quality, right quantity (volume), partnerships and procurement procedures are appropriate, and other agreements in accordance with the agreements made so that the user can utilize the goods / service in question. To get the goods or services in question are the basic principles that must be followed. The principle in the procurement of goods or services are efficient, effective, open, competitive, transparent, fair and non-discriminatory, and accountable. Therefore, the basic principles of the legal basis for the parties (providers and users), and if it does not follow the basic principles are intended to deal with law enforcement.

Procurement system of goods and services that is existing in Indonesia still have a disadvantage in preventing corruption. Procurement of goods and services remains a separate opportunity for the parties who are not responsible for utilizing the ineffectiveness of procurement of goods or services. Due to the chance of irregularities in the implementation of the goods and services in government agencies, then the best solution for solving the problem is to use e-Procurement system. e-Procurement is one of the best approach to preventing the abuse of duties and responsibilities in the procurement of government goods and services. With the e-Procurement, direct contact between the supplier of goods or services procurement committee becomes lower, so that the procurement process can take place more transparently, saving time and cost, and easy in its financial accountability.

In current e-procurement system is still incomplete. On the current system, there has been no classification of goods and services as well as classification of the type of business fields in Indonesia. This causes every field of business can follow all kinds of goods and services held by the government and did not result in a business field focuses on a field. A vendor that does not focus on the type of business that was involved field makes the vendor has a field that is too broad to be less professional or expert in one field there. Moreover, there are still quite a lot of vendors who wins the auction despite the poor performance in the past auction. Therefore, it needs to be reduced so that the results of the auction could be better and better again. 


\section{RELATED WORKS}

SPSE or electronic procurement system [1] is a system used to perform the procurement or tendering of goods or services by the Indonesian government. This system was developed by the city government of Surabaya and later adopted by the Indonesian government since 2007 until now. [19]This system has been used on more than 620 government agencies throughout Indonesia under the supervision LKPP as an institution responsible for the procurement of government goods and services. In this system, to assess the potential winner, offers, and others are still manually, so sometimes something goes wrong in the process.

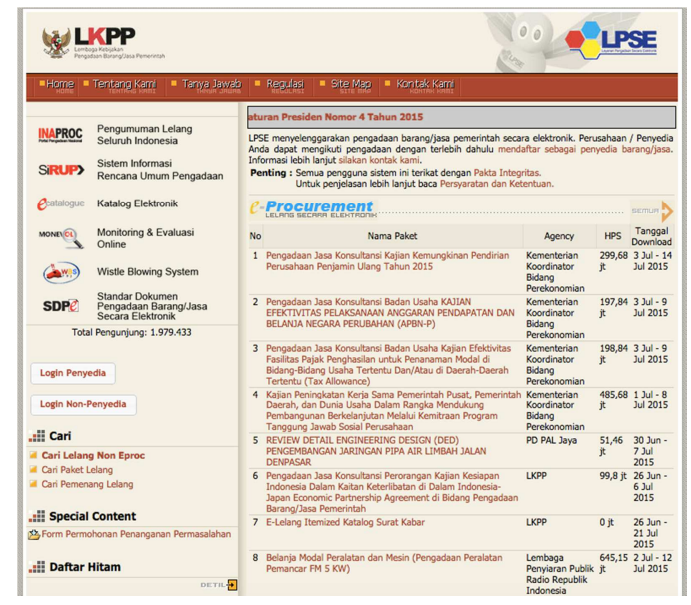

Figure 1. Current E-Procurement System

Several research related to the decision support system has been conducted before. [3] proposed the evaluation system of the tenders is completely pre-defined upon the multi-criteria analysis principles: the offering company will know the criteria in advance, and will be able to score its own tender before submission in order to guarantee the fairness and transparency of procedures. Criteria are related to the cheapness for the commissioning authority, the coverage and the capillarity of the supplied service, the quality, the information to clients.

In paper [4], the authors proposed The Integrated Web-based DSS comprises a Process Modelling for Online Communication System (PMOCS), a Web-based DSS and, a Decisioning for Decision Support in Process (D2P). The goal of this research is to employ a generic application for supporting complex and unstructured decision problems in the tendering process within the construction industry by developing an Integrated Web-based DSS for supporting the tendering processes that facilitates real time communication and coordination between clients, contractors and consultants using process support technologies.

Paper [5] propose to introduce computer assistance to tendering procedures, i.e. to substitute intellectual and manual labor of the bid holder 
meant to choose an appropriate contractor with the automated system aiding decision-making (SADM). Choosing the successful bidder through procedures of tender for oil and gas fields imposes high level of responsibility for the decisionmaker on the bid holder to the tenderers, the decision is time restricted and demands unconventional thinking.

Lam, K. C., et al. [6] developed and tested the neural network model for contractor pre-qualification, and demonstrated the feasibility of the approach via theoretical analysis and case study. In this study, real pre-qualification cases and hypothetical pre-qualification cases had been compiled for the training and validating of the neural network. It is shown that this approach is capable of modeling the complex relationship between contractor attributes and the client's pre-qualification decision and is capable of achieving satisfactory accuracy.

\section{ORIGINALITY}

E-Procurement is the process of purchasing goods and services electronically. Purchases of goods and services conducted by the Indonesian government are set in a regulation which for the purchase of goods or services with a particular value using the electronic auction is often called the E-Tendering. It is very important for a country, especially Indonesia, therefore, it need to be improved in some parts of this process to increase its effectiveness and efficiency.

In several papers that have been mentioned before, they have written a few things in the auction process but no one has discussed about the classification of goods and services (UNSPSC) and standard classification of business field.

In this study, we proposed a new model of E-Tendering system by combining the classification of goods and services [7] and Indonesian business sector classification standard (KBLI 2009)[2]. Beside that, to facilitate and improve the accuracy in selecting the winning candidates also to prevent not eligible winner, in this system also included a vendor management system to keep track of the vendors that will be used as input material selecting potential winners using AHP.

\section{SYSTEM DESIGN}

To overcome existing deficiencies in the previous system, we offer a solution in which there will be implemented the classification of goods and services based on UNSPSC (United Nations Standard Products and Services Code) and collaborate with Indonesian Standard Industrial Classification 2009 edition for later procurement of goods and services in Indonesia better. 


\section{E-Tendering Express Design}

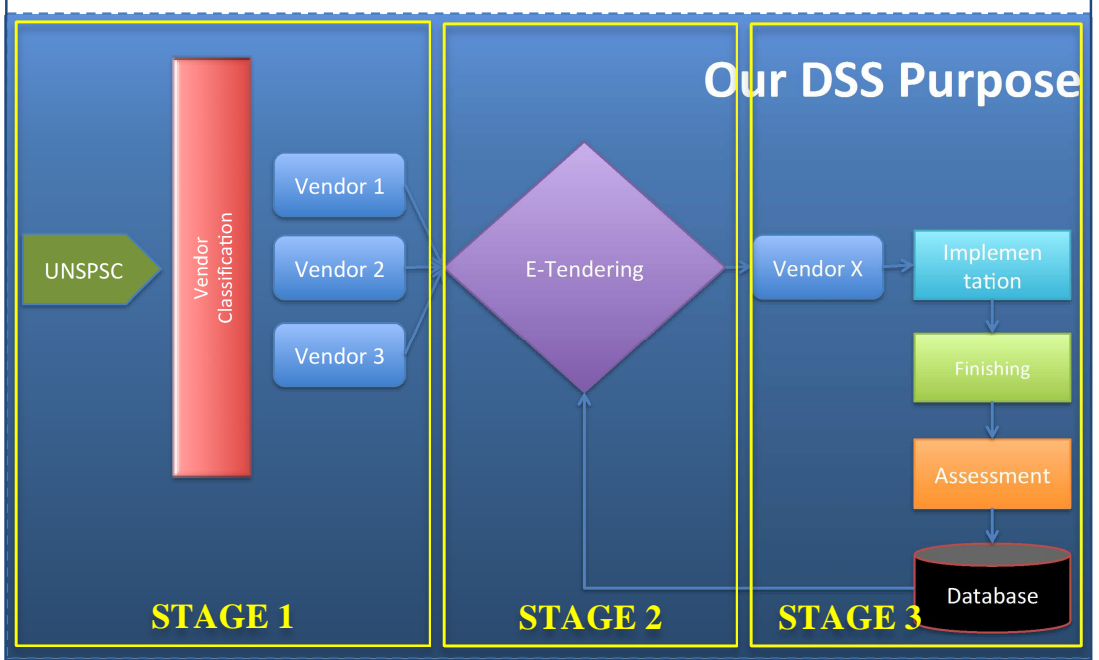

Figure 2. E-Tendering Design System

In Figure 2, explain that This system divide e-Tendering process into several stages. (1) Stages 1 : finding suitable business sector classification for the classification of goods and services that have been chosen to be auctioned. In this stage, we are using text mining to find the suitable classification. (2) Stages 2 : provides rankings for each vendor who participate in the auction through AHP with predetermined weighting using the track record of each vendor which saved in the vendor management system database. (3) Stage 3: in this last stage, after the work is completed, the results will be assessed and stored in the database for evaluation on the upcoming auction.

There are quite significant difference in the system that we made compared to the running system or with the e-Catalog system. The differences include from the start of the time required for the auction, the accuracy of vendor selection, and also the history of each vendor.

Table 1. System Comparison

\begin{tabular}{|c|c|c|c|}
\hline Feature & $\begin{array}{l}\text { Current } \\
\text { System }\end{array}$ & E-Katalog & Our System \\
\hline Complexity & High & Low & High \\
\hline $\begin{array}{ll}\text { Decision } & \text { Support } \\
\text { System } & \end{array}$ & No & No & Yes (using AHP) \\
\hline $\begin{array}{ll}\text { Vendor } & \text { Auction } \\
\text { History } & \\
\end{array}$ & No & No & $\begin{array}{c}\text { VMS (Vendor } \\
\text { Management System) }\end{array}$ \\
\hline Vendor Classification & No & No & KBLI 2009 \\
\hline $\begin{array}{l}\text { Goods/Services } \\
\text { Classification }\end{array}$ & No & No & UNSPC \\
\hline Required Time & Long & Short & Medium \\
\hline
\end{tabular}


In Table 1, describe the difference between current system (SPSE), ECatalog, and our proposed system. E-Tender has several levels of complexity. For low complexity, such as the procurement of computers, or other items that have been standard specifications can usually be done using e-catalogs, while for the category of high complexity can not be done by e-catalogs. For example, the computer which needs custom specifications. Current E-Tender system is not using classification, both the classification of vendor and the classification of goods or services. Our proposed system offers these classifications to make the auctions more effective and efficient. In our proposed system also offer a decision support system(DSS) that utilizes vendor management system as the history of each vendor, so that the committee can easily select the candidate winning bidder. It can also cut back the auction time so that it can be more faster.

\section{A. Vendor Classification Process}

Vendor Classification is a process that used to find suitable vendor who can follow the current auction.

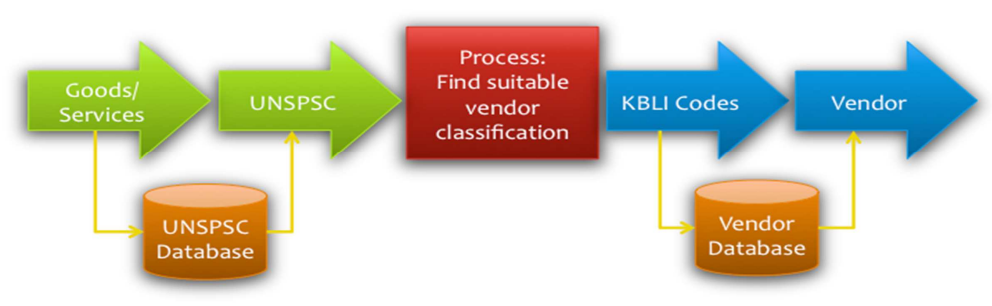

Figure 3. Vendor Classification Process

Vendor classification in accordance with the classification of goods and services that have been determined by using text mining. Before discussing into the text mining, it will be clarified in advance what the UNSPSC and KBLI 2009 and their respective structures.

\section{A.1. UNSPSC [7]}

UNSPSC is an efficient, accurate and flexible classification system for achieving company-wide visibility of spend analysis, as well as, enabling procurement to deliver on cost-effectiveness demands and allowing full exploitation of electronic commerce capabilities. Encompassing a five level hierarchical classification codeset, UNSPSC enables expenditure analysis at grouping levels relevant to your needs. You can drill down or up to the codeset to see more or less detail as is necessary for business analysis.

The UNSPSC offers a single global classification system that can be used for:

- Company-wide visibility of spend analysis.

- Cost-effective procurement optimization. 
- Full exploitation of electronic commerce capabilities.

\section{How does UNSPSC work?}

\section{Segment}

The logical aggregation of families for analytical purposes

XX Family

A commonly recognized group of inter-related commodity categories

\section{Class}

A group of commodities sharing common characteristics

\section{Commodity}

A group of substitutable products or services

\section{Business Function}

The function performed by an organization in support of the commodity.

All UNSPSC entities are further identified with an 8-digit structured numeric code which both indicates its location in the taxonomy and uniquely classifies it. An additional 2-digit suffix indicates the business function identifier. A structural view of the code set would look as follows:

Table 2. UNSPSC Example

\begin{tabular}{|l|l|l|}
\hline Hierarchy & $\begin{array}{c}\text { Category } \\
\text { Number }\end{array}$ & Name \\
\hline Segment & 43 & $\begin{array}{l}\text { Information Technology Broadcasting and } \\
\text { Telecommunications Communications Devices and } \\
\text { Accessories }\end{array}$ \\
\hline Family & 20 & $\begin{array}{l}\text { Components for information technology or } \\
\text { broadcasting or telecommunications Computer } \\
\text { Equipment and Accessories }\end{array}$ \\
\hline Class & 15 & Computers Computer accessories \\
\hline Commodity & 01 & Computer switch boxes Docking stations \\
\hline $\begin{array}{l}\text { Business } \\
\text { Function }\end{array}$ & 14 & Retail \\
\hline
\end{tabular}

\section{A.2 KBLI 2009}

Klasifikasi Baku Lapangan Usaha Indonesia or Indonesian Standard Industrial Classification (ISIC) is a standard classification of economic activities are located in Indonesia[2]. ISIC 2009 arranged to provide a set framework of a comprehensive classification of economic activities in Indonesia to be used for the uniform collection, processing, presentation and analysis of statistical data according to economic activity, as well as to study the economic situation and performance according to economic activities. 
With the uniformity, statistical data of economic activity can be compared to a standard format at the national, regional, and international levels[3].

KBLI 2009 classify the whole activity/economic activity in several fields of business activities which are distinguished based approach that emphasizes the process of economic activities in creating the goods/services, and approach more functions look at the functions of economic actors in creating the goods or services. The business unit is not differentiated according to the status of ownership, type of legal entity, or mode of operation. Production units which perform the same economic activity are classified in the same group of KBLI 2009, regardless of whether the production units are part of a legal entity or not, private or government, or individual, even if derived from enterprise consisting of more than the establishment or not.

\section{KBLI 2009 Code Structure}

a. Category, shows a line of staple classification of economic activities. This classification is coded one-digit code alphabet. In KBLI 2009, all economic activities in Indonesia are classified into 21 categories. The categories are coded letters from A to U.

b. Principal Class, a further description of the category. Each category is broken down into one or several base classes (up to five groups of goods, except for processing industry) according to the nature of each base class. Each subject was given a class of two-digit code.

c. Class, a further description of the principal class (point b). Class code consists of three digits, the first two digits indicate the principal class concerned, and the last digit indicates the economic activities of each class are concerned. Each base class can be broken down into as many as nine classes.

d. Sub-class, a further description of economic activity covered by a class (item c). Sub-class code consists of four digits, which is the first three-digit code shows the class-related, and the last digit indicates the economic activities of the Sub-class concerned. Each class can be broken down further into as many as nine sub-class.

e. Groups, is intended to break down the activities which are covered by a 'sub class' into several more homogeneous activities.

Table 3. KBLI 2009 Code Structure [2]

\begin{tabular}{|lc|c|}
\hline \multicolumn{2}{|c|}{ KBLI 2009 Structure } & Qty \\
\hline Category & (alphabet) & 21 \\
\hline Principal Class & (2 digits) & 88 \\
\hline Class & (3 digits) & 241 \\
\hline Sub class & (4 digits) & 514 \\
\hline Groups & (5 digits) & 1457 \\
\hline
\end{tabular}


B. Text Mining

Just as data mining can be loosely described as looking for patterns in data, text mining is about looking for patterns in text[8]. However, the superficial similarity between the two conceals real differences. Data mining can be more fully characterized as the extraction of implicit, previously unknown, and potentially useful information from data. The information is implicit in the input data: it is hidden, unknown, and could hardly be extracted without recourse to automatic techniques of data mining. With text mining, however, the information to be extracted is clearly and explicitly stated in the text. It's not hidden at all-most authors go to great pains to make sure that they express themselves clearly and unambiguously and, from a human point of view, the only sense in which it is "previously unknown" is that human resource restrictions make it infeasible for people to read the text themselves. The problem, of course, is that the information is not couched in a manner that is amenable to automatic processing. Text mining strives to bring it out of the text in a form that is suitable for consumption by computers directly, with no need for a human intermediary[8].

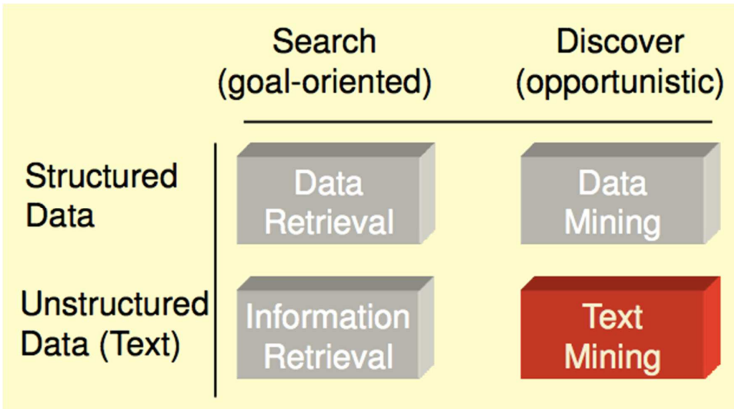

Figure 4. Text Mining [18]

The text mining process have a few part, such as tokenizing, filtering, stemming/lemmatization, tagging, analyzing. Tokenizing is a process to break the sentence into word per word before proceeding to the next stage. There will be still a few more stages thereafter are discussed in more detail in the next section. 


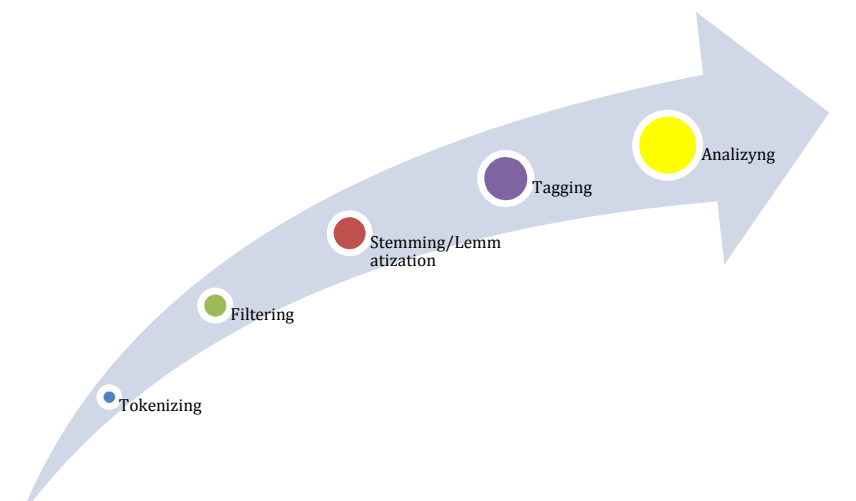

Figure 5. Text Mining Process [18]

\section{Tokenizing}

Tokenization, or splitting the input text into words, is an important first step that seems very easy but is fraught with small decisions: how to deal with apostrophes and hyphens, capitalization, punctuation, numbers, alphanumeric strings, whether the amount of white space is significant, whether to impose a maximum length on tokens, what to do with nonprinting characters, and so on. It may be beneficial to perform some rudimentary morphological analysis on the tokens[8].

Tokenization is a critical activity in any information retrieval model, which is simply segregates all the words, numbers, and their characters etc. from given text or document and these identified words, numbers, and other characters are called tokens.

\section{Filtering}

Filtering helps to provide the flexibility when we want to design data sources and mining structure so that a single mining structure can be created based on the comprehensive data source view. For training and testing different models, filters can be created to use only a part of that data and no need to build a different structure for each subset of data. We can use filter by length, Content, Indonesian, dictionary and Region etc. Filtering stage is the stage of taking important words from the tokens we have created. Could use the algorithm stop list (discard the less important word) or word list (save important words).

In this paper tokens are filtered by length and words stop list. This operator filters tokens based on their length (i.e. the number of characters they contain) and stop list words. Parameters used in this operator to check length are:

- min chars:- The minimal number of characters that a token must contain to be considered.

- max chars:- The maximal number of characters that a token must contain to be considered. 


\section{Stemming}

Stemming also known as lemmatization is a technique for the reduction of words into their stems, base or root. Many words in the Indonesian language can be reduced to their base form or stem e.g. Moreover, names can be transformed into root by removing the "s", for e.g., During the stemming process the variation "Stem's" in a sentence is reduced to "Stem" and this removal may lead to an incorrect stem or root. However, if the words are not used for human interaction then, these stems do not have to be a problem for the stemming process. But the stem is still useful, because all other inflections of the root are transformed into the same root.

In linguistic morphology and information retrieval, stemming is the process for reducing inflected (or sometimes derived) words to their stem, base or root form-generally a written word form. The stem need not be identical to the morphological root of the word; it is usually sufficient that related words map to the same stem, even if this stem is not in itself a valid root. Algorithms for stemming have been studied in computer science since the 1960s. Many search engines treat words with the same stem as synonyms as a kind of query expansion, a process called conflation.

Lemmatisation (or lemmatization) in linguistic, is the process of grouping together the different inflected forms of a word so they can be analysed as a single item.

In computational linguistics, lemmatisation is the algorithmic process of determining the lemma for a given word. Since the process may involve complex tasks such as understanding context and determining the part of speech of a word in a sentence (requiring, for example, knowledge of the grammar of a language) it can be a hard task to implement a lemmatiser for a new language.

In many languages, words appear in several inflected forms. For example, in English, the verb 'to walk' may appear as 'walk', 'walked', 'walks', 'walking'. The base form, 'walk', that one might look up in a dictionary, is called the lemma for the word. The combination of the base form with the part of speech is often called the lexeme of the word.

Lemmatisation is closely related to stemming. The difference is that a stemmer operates on a single word without knowledge of the context, and therefore cannot discriminate between words that have different meanings depending on part of speech. However, stemmers are typically easier to implement and run faster, and the reduced accuracy may not matter for some applications.

\section{Tagging}

Tagging stage is the stage of seeking an early form / root of each word or words past results stemming. Some words are usually undergo morphological changes shape into another word. For that there is the need to return it to its original shape 


\section{Analyzing}

Analyzing stage is the stage of determining how much connectivity between words between documents or text which mined. Term FrequencyInversed Document Frequency (TF-IDF) is the most simple algorithms that are usually used for scoring but still not optimal in this case because it rarely produces the expected document. In this text mining, we propose a new method/formula to give a score to each document. In this new formula we departed from the spirit of the balance of the search terms proportional to the number of words in the document. The formula is described below:

$$
\operatorname{Vfkmax}_{n}=\frac{S W_{n}}{k}
$$

If $\mathrm{fk}_{\mathrm{n}, \mathrm{i}}<\mathrm{Vfk}_{\max }$

$$
r_{n, i}=\frac{f k_{n, i}}{S W_{n}}
$$

else

$$
\begin{gathered}
r_{n, i}=\frac{V f k \max _{n}}{S W_{n}}+\frac{f k_{n, i}-V f k \max _{n}}{S W_{n} \cdot k} \\
R_{n}=\sum_{i=1}^{n} r_{n, i}
\end{gathered}
$$

$r_{n, i} \quad=$ score of each keyword i in document $\mathrm{n}$

$n \quad=$ total number of documents

$k \quad=$ number of many keywords

$f k_{n, i} \quad=$ number of found keyword i in document $\mathrm{n}$

$S W_{n} \quad=$ number of words in document $\mathrm{n}$

Vfkmax $_{n} \quad=$ Maximum value for each keyword in document $\mathrm{n}$

$R_{n} \quad=$ Score of document $\mathrm{n}$

The formula above has been tried and compared to some other method for example such as TF-IDF and TF.

\section{Determine the Potential Winner}

To select the potential winner, the system uses the parameters retrieved from the database that previously been included in the assessment process carried out after a job is completed. The parameters used are as follows: 
Table 4. AHP Parameters

\begin{tabular}{|l|l|c|}
\hline No & \multicolumn{1}{|c|}{ Parameters } & Weight \\
\hline 1 & Performance \& Quality (PQ) & 4 \\
\hline 2 & Adherence to Specifications (AS) & 3 \\
\hline 3 & Amount of Claims (AC) & 1 \\
\hline 4 & Failure (FL) & 2 \\
\hline 5 & Price (PR) & 5 \\
\hline
\end{tabular}

Here is the global process to select a winner:

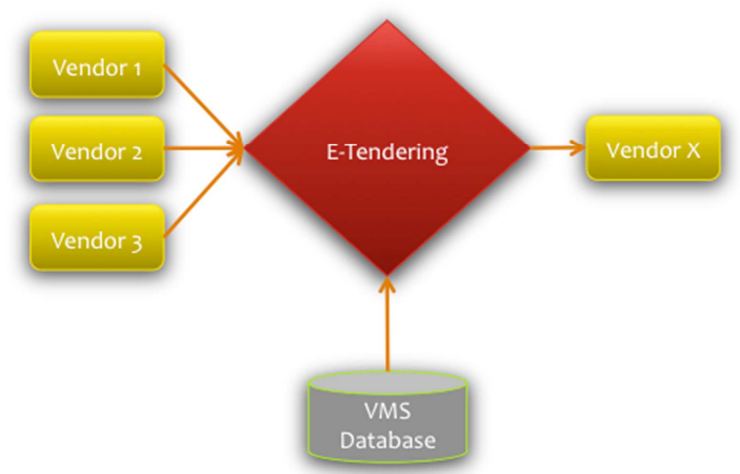

Figure 6. Selecting a Winner

All the above parameters will be calculated to produce a potential winner of the auction. The method used is the AHP (Analytic Hierarchy Process). Here is its system design:

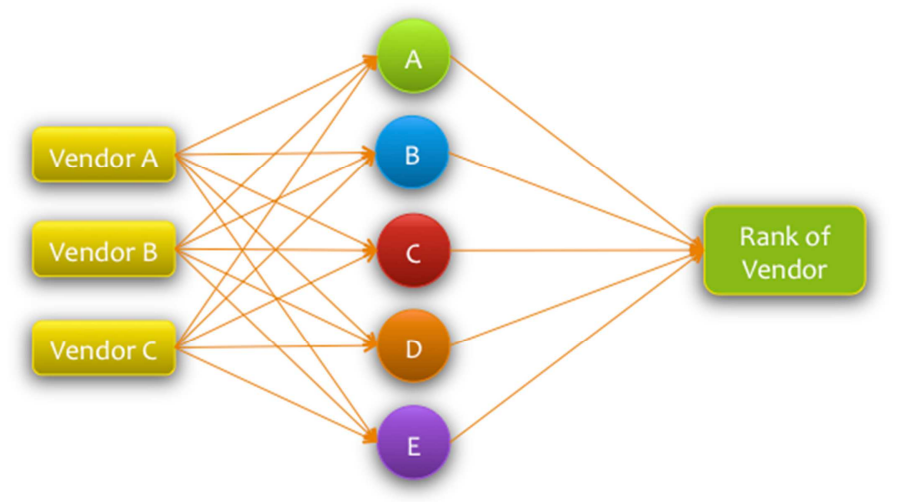

Figure 7. AHP Modeling

\section{Vendor Assessment}

The current system does not have a complete Vendor Management System. So, in this research will be included the new vendor management 
system which can save a track record from the vendor. In this section, will be show how to give an assessment to a vendor after they finish their works:

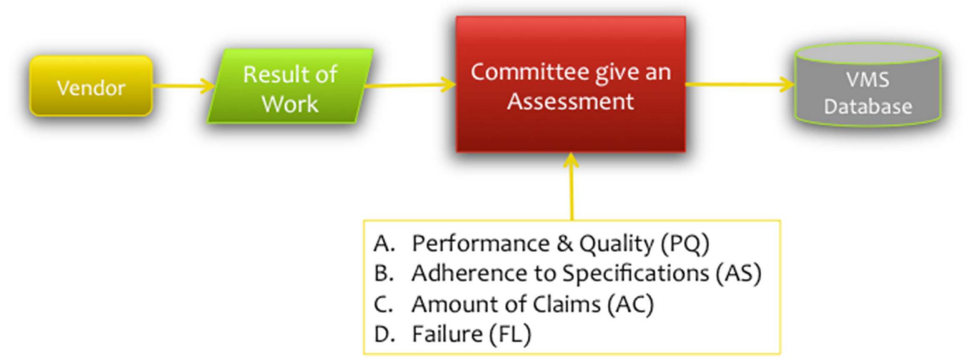

Figure 8. Vendor Assessment Process

In the assessment process, the committee will give an assessment in 4 parameters, that are Performance \& Quality (PQ), Adherence to Specifications (AS), Amount of Claims (AC), and Failure (FL). All of that parameters will be given in a point score system in the following table:

Table 5. Point Score System[6]

\begin{tabular}{|c|c|c|c|c|c|c|c|c|}
\hline Poor & & Fair & & Good & & Very Good & & Excellent \\
\hline $1 \sim 2$ & $3 \sim 4$ & $5 \sim 6$ & $7 \sim 8$ & $9 \sim 11$ & $12 \sim 14$ & $15 \sim 16$ & $17 \sim 18$ & $19 \sim 20$ \\
\hline
\end{tabular}

\section{EXPERIMENT AND ANALYSIS}

System is tested on another system with combined way. This system is a small part of a larger system that is e-procurement which currently still in the design stage.

Experiments carried out first by entering keywords to search for goods or services that exist in the list of UNSPSC and after that it will appear UNSPSC which has the closest relationship to the keywords in question.

Having obtained the appropriate UNSPSC code, it will look for a suitable business classification to UNSPSC codes that have been selected by using correlation measurements.

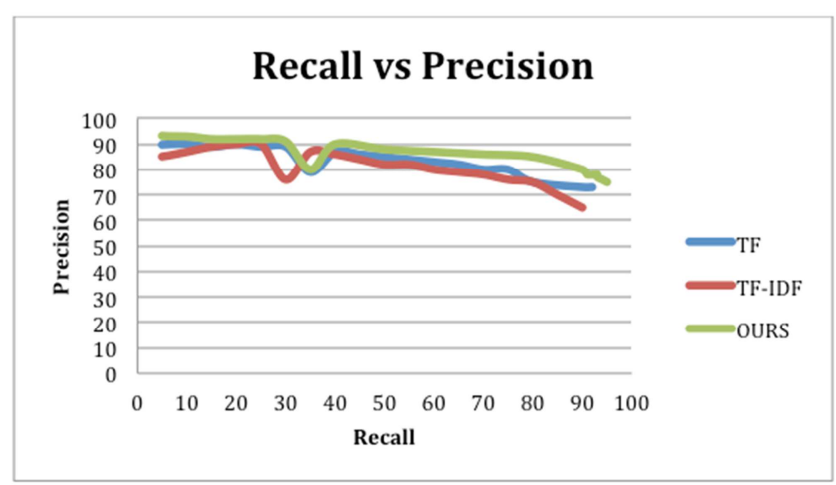

Figure 9. Text Mining Recall vs Precission 
Figure 9 shows the results of a test method for assessing the outcome document text mining. There are three methods tested, namely TF, TF-IDF, and our proposed system. From these results, it shows that our proposed system has an even better value than the other two methods, especially for this case.

Based on some of the results of experiments that have been done, we developed a new method is more suitable for this case in comparison with other methods such as TF and TF-IDF.

The process of assessment of the work carried out by officials who have been appointed. This value will be used as a benchmark for assessment at the next projects to be undertaken by the vendor. The value will be stored in a database vendor management system. Here are the test results of the assessment results that have been recorded last activity by some vendors to bid on an auction:

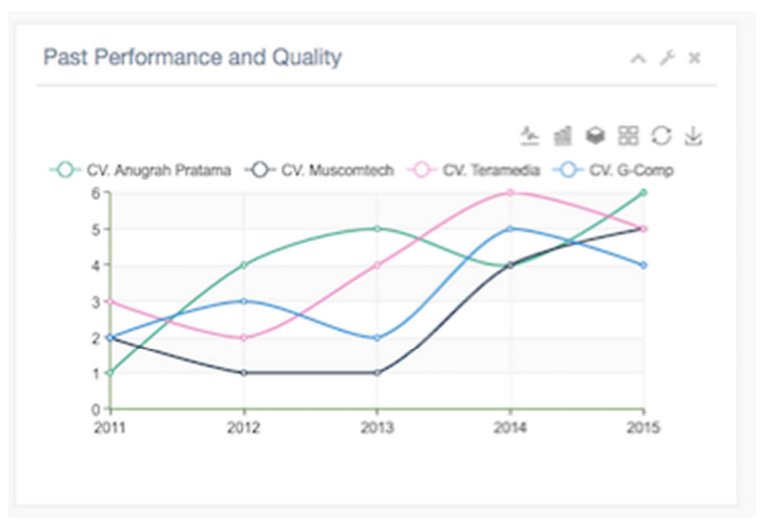

Figure 10. Past Performance and Quality

In Figure 10: Past Performance and Quality is data that contains the performance and quality of the each vendor that are following the auction. This data is stored in a database management system vendor and taken for the last 5 years. The better the performance and quality of the past work, then it will be better for the judgment.

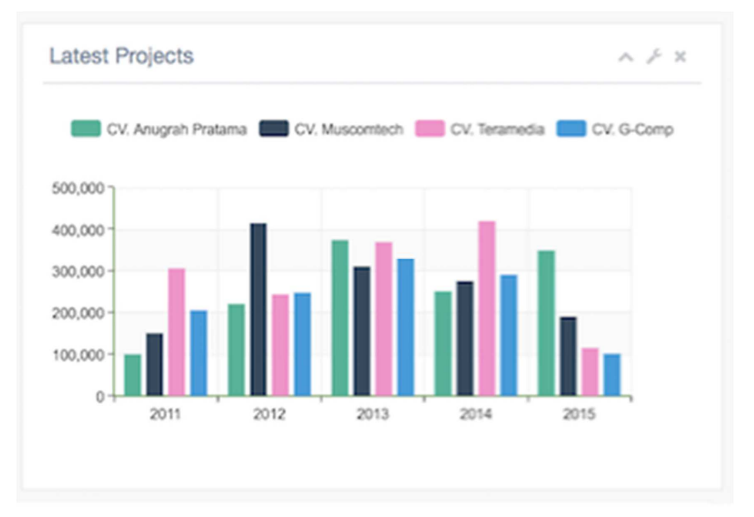

Figure 11. Latest Project 
In figure 11: Latest Project is a graph drawn from the data last auctions done by each vendor. This data was also collected from the vendor database management system. From this data it can be seen the value of total jobs vendor during the last five years. More and more get the auction, it will be well worth.

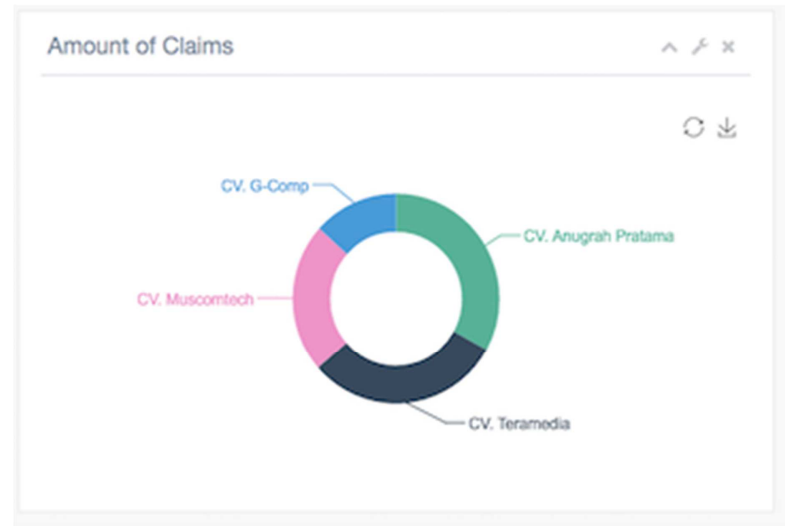

Figure 12. Amount of Claims

Figure 12 displays amount of claims from each vendor. These data were also obtained from a vendor management system are taken as the last 5 years then accumulated. The less amount of claims are better.

In addition to measuring the last activity of vendors, also included in several other parameters for Analytical Hierarchy Process such as the proximity, adherence to specifications, and price.

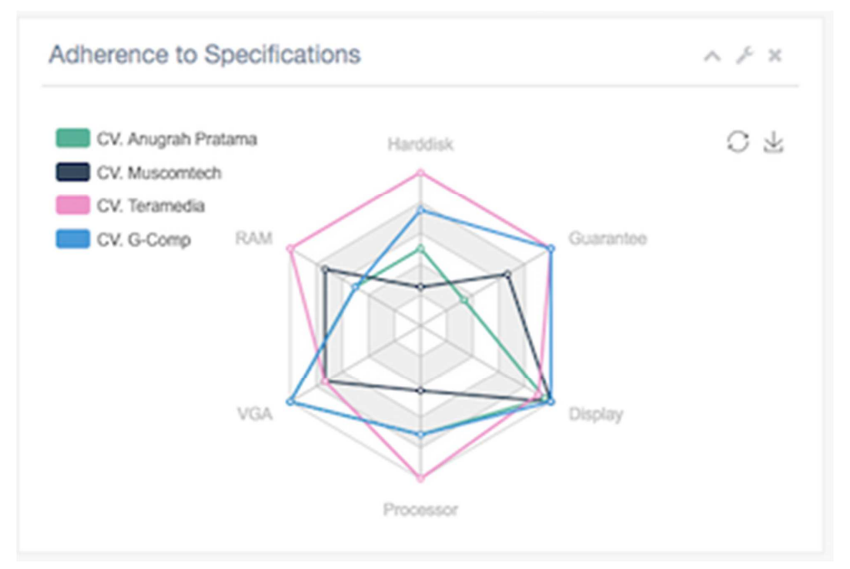

Figure 13. Adherence to Specifications

In figure 13 displays the specifications of each vendor offers. Specifications are closer to the needs of the auction will get better value.

After all the parameters in AHP has been fulfilled, the process can be done to get the prospective winner of the auction. 


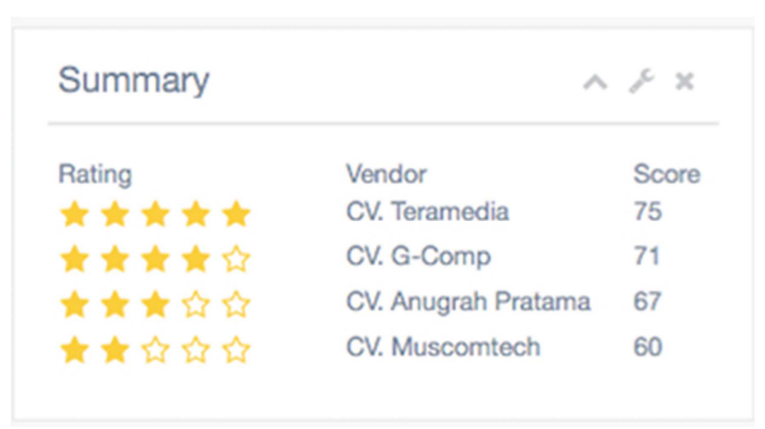

Figure 14. Summary of AHP Result

Figure 14 illustrates the results of the calculation of some of the above parameters(Past Performance and Quality, Latest Projects, amount of claims, adherence to specifications, price and proximity). The calculations obtained through Analytical Hierarchy Process. The highest value will get a star at most. From this figure above, we can see that the CV. Teramedia is the most appropriate winner candidate to win the ongoing tender.

\section{CONCLUSION \& FUTURE WORKS}

There are still some deficiencies or loopholes in the running system that can be exploited by some vendors to take advantage as much as possible. Indonesia could lose considerable amounts of money because of this. This must be fixed as soon as possible.

Therefore, this paper offers some solutions, for example such as the classification of goods or services. The classification of the goods or services can make the vendor become more professional. The activities of related vendor that has been done by them are well documented, both from the quality of work, claims, and others making it possible to know the achievements of providers before selecting them to be a winner. For those who have a poor performance will get lower points at the next auction. It is yet to be accommodated on a system that is running now.

UNSPSC facilitate in determining the goods or services to be auctioned because it is divided according to the classification. The classification facilitate the committee to select the products or services quickly and accurately. ISIC 2009 classifies companies according to the field that they do so could be more professional. Vendor Management system record all activities of each vendors. The data can be used to assess the performance of providers and very helpful to choose and to know that qualified providers using AHP.

Our future works include the application of text mining to evaluate the bidding documents automatically. In addition, we also would like to optimize the process of e-tender so that the auction could be simpler and faster again. 


\section{REFERENCES}

[1] Presidential Decree No.4 of 2015

[2] Head of The Central Statistics Regulation Number 57 of 2009.

[3] Michela Burla, Eliot Laniado, Fosca Romani, Paola Tagliavini, The Role of Decision Support Systems (DSS) in Transportation Planning: the Experience of the Lombardy Region, Seventh International Conference On Competition And Ownership In Land Passenger Transport Molde, Norway, June 25-28, 2001.

[4] N.M. Mohamad Noor, K.N. Papamichail, B. Warboys, An Integrated WebBased Decision Support System For Tendering Processes, Joint International Conference on Computing and Decision Making in Civil and Building Engineering, Montréal - Canada, June 14-16, 2006.

[5] Anna Khripunova, Konstantin Vishnevskiy, Oleg Karasev, Dirk Meissner, Intelligent Data Systems To Aid Decision-Making At Tenders For Oil And Gas Fields Development, Working Paper Science And Technology And Innovation: WP BRP 07/STI/2013, National Research University Higher School Of Economics (HSE), Moscow, Russia, 2013.

[6] Lam, K. C., et al. Decision support system for contractor pre-qualificationartificial neural network model, Engineering, Construction and Architectural Management 7.3 (2000): 251-266.

[7] Michael Rebstock, Fengel Janina, Heiko Paulheim, Ontologies-Based Business Integration, Springer Science \& Business Media, Feb 28, 2008.

[8] Munindar P. Singh, The Practical Handbook of Internet Computing, CHAPMAN \& HALL/CRC Computer and Information Science Series, 2005.

[9] Vikram Singh and Balwinder Saini, An Effective Tokenization Algorithm For Information Retrieval Systems, Departement of Computer Engineering, National Institute of Technology Kurukshetra, Haryana, India, 2014.

[10] Tanu Verma and Renu and Deepti Gaur, Tokenization and Filtering Process in RapidMiner, International Journal of Applied Information System (IJAIS), 2014.

[11] Joel Larocca Neto and Alexandre D. Santos and Celso A.A. Kaestner and Neto Alexandre and D. Santos and Celso A. A and Kaestner Alex and Alex A. Freitas, Document Clustering and Text Summarization, Pontificia Universidade Catolica do Parana, Postgraduate Program in Applied Computer Science, Brazil, 2000.

[12] Martin Hepp, Joerg Leukel, and Volker Schmitz, A Quantitative Analysis of Product Categorization Standards: Content, Coverage, and Maintenance of eCl@ss, UNSPSC, eOTD, and the RosettaNet Technical Dictionary, Springer, 2006

[13] Leo Obrst Robert E. Wray Howard Liu, Leo Obrst Robert E. Wray Howard LiuOntological Engineering for B2B E-Commerce, Proceedings of the international conference on Formal Ontology in Information Systems, 2001

[14] Bjornar Larsen and Chinatsu Aone, Fast and effective text mining using linear-time document clustering, Proceedings of the fifth ACM SIGKDD international conference on Knowledge discovery and data mining, 1999 
[15] Weiguo Fan, Linda Wallace, Stephanie Rich, Zhongju Zhang, Tapping the power of text mining, Magazine Communications of the ACM - Privacy and security in highly dynamic systems, Volume 49 Issue 9, September 2006

[16] Tuomo Kakkonen and Tabish Mufti, Developing and applying a company, product and business event ontology for text mining, Proceedings of the 11th International Conference on Knowledge Management and Knowledge Technologies, 2011

[17] Yue Dai, Tuomo Kakkonen, Erkki Sutinen, MinEDec: a Decision-Support Model That Combines Text-Mining Technologies with Two Competitive Intelligence Analysis Methods, International Journal of Computer Information Systems and Industrial Management Applications, 2011

[18] Nathan Treloar, AvaQuest, Text Mining: Tools, Techniques, and Applications, Knowledge Technologies Conference 2002 / Westin Seattle Hotel - Seattle, WA - USA, March 11-14, 2002.

[19] http://report-lpse.lkpp.go.id, Lembaga Kebijakan Pengadaan Barang/Jasa Pemerintah.

[20] Kementerian Keuangan Republik Indonesia, Direktorat Penyusunan APBN, Direktorat Jenderal Anggaran, Informasi APBN 2016. 